\title{
Loss of Innocence
}

A number of years ago, in a conversation with Walt Rosen, an old friend who at the time was living in Washington, D.C., I was holding forth on the value of restoration as a conservation strategy, a way of achieving a healthy relationship with nature, etc., and Walt stopped me with a question.

"That's great," he said. "But perhaps you push it too far. Restoration is a good thing, obviously. But doesn't it involve a sort of loss of innocence?"

That was all. It seemed to be true. It also seemed somehow more interesting than damaging to my case. I didn't know where to go with it. But somehow, it stayed with me.

Then last spring, at the suggestion of another friend, I read a small book by R.W.B. Lewis called The American Adam: Innocence, Tragedy, and Tradition in the Nineteenth Century. And there I came across some ideas that helped me think through Walt's question about restoration and the loss of innocence, and also led me to some new ideas about the limitations of environmentalism, and how restoration can help correct them.

Lewis's book, published in 1955, is an account of the attempt of American writers during the 19th century to develop an American literature distinct from that of Europe. Doing this meant, among other things, figuring out what the American story was about. Most writers took it for granted, Lewis writes, that the great American story, the story that distinguished America from Europe and the rest of the Old World, was a new version of the old story of the Garden of Eden. If America was the new Eden, unspoiled by history, then the American was a new Adam (and, we might add, Eve), starting from scratch to build a new world.

This of course raised the question of innocence. If Adam and Eve-and all of nature-were innocent (at least at the beginning of the story), what about the European immigrant, who carried the burden of several millennia of history, much of it reflecting all too clearly the mark of the serpent-original sin?

What to do about the old Judeo-Christian notion of original $\sin$ ? What, in fact, to do about the past and its moral and psychological burdens?

According to Lewis, American writers offered three very different answers to these questions. The first was the Calvinist idea, then predominant in American society, that humans, along with the rest of nature, were truly fallen, and could not be redeemed as a result of their own effort.
The second was the idea, developed by writers who made up what Lewis calls the Party of Hope, that, while humans may have fallen, nature did not. If humans were corrupt, nature at least remained unspoiled - a repository of innocence. Thus, redemption is possible, and can be achieved by stripping away the distractions and corruptions of culture and immersing oneself in unspoiled nature.

Foremost among writers who adopted this view were Emerson, Thoreau and Whitman - all of whom are of special importance to us because in their different ways each of them helped lay the foundations for the environmental thinking of our own time.

This, I now suspect, is the origin of our misgivings about restoration as a loss of innocence. Restoration certainly does involve the mixing of nature with culture, and, as intellectual descendants of the party of hope, we see that as corruption-a step in the wrong direction.

Yet if the testimony of imaginative literature is of any value in sorting these things out, it may well be that this is a mistake. Innocence means, at root, harmless, or not knowing harm. Yet since nature is full of harm, the knowledge of harm - and the loss of innocence-is a prerequisite to communion with it.

Thus, according to Lewis, by idealizing innocence the Emersonians actually condemned themselves to a kind of moral and psychological childhood, precluding communion, and laying the foundations for the literature of alienation that has dominated our own century.

Contrasting with this view, however, was that developed by a third party, which Lewis calls the Party of Irony. Most familiarly represented today by Nathaniel Hawthorne and Herman Melville, the "ironists" saw a principle of badness or monstrousness in nature as well as in human life (think, for example, of Melville's famous whale), and so saw a moral and psychological continuity between nature and culture-a continuity of shame.

Moreover, they discovered in the course of their literary "experiments" that it is precisely in confronting this monstrousness, acknowledging the continuity of shame, that one achieves redemption or, we may say, communion.

In reaching this conclusion, Lewis notes, the ironists had, in fact, rediscovered the old idea that the way to community lies through the knowledge of shame. He points out that this idea 
was represented in medieval Christianity by the idea of the "fortunate fall"- the realization that it was precisely through the sin in the Garden that humans achieved moral maturity-and with it the capacity to enter into community.

And, though Lewis does not discuss this, we may add that the same idea is characteristic of premodern and archaic societies generally, with their lively sense of what mythologist Joseph Campbell has called, in an arresting phrase, "the monstrousness of the just so."

Hence the ritual institutions for confronting shame and passing through shame to community characteristic of such premodern traditions and cultures: ritual killing and eating as a paradigm of communion; and the psychologically harrowing - and often physically violent-rituals of initiation that effect the passage from childhood to adulthood and citizenship.

Lost, or nearly so, to the modern West, this idea that redemption and community are achieved only by passing through shame was explored again in works of fiction such as Hawthorne's The Marble Faun and Melville's late novel Billy Budd.

Which brings us back to Walt Rosen's question about restoration and the loss of innocence. Yes, restoration does involve the loss of innocence, the abandonment of the idea of nature pure and separate from ourselves-perhaps that is the most valuable thing about it. If, as the ironist Henry James (father of the well known writer of the same name) wrote, Eve's service to Adam was that she coaxed him into the moral crisis necessary to gain the knowledge of shame, then perhaps the same thing is true of the restorationist-perhaps it is her job to draw us out of in- nocence and into shame, into acknowledging, in Fred Turner's phrase, our solidarity in crime with the rest of nature, and so into communion with it.

Clearly, the restorationist confronts shame, defined as a painful awareness of limitation or fault, in many ways-in acknowledging the injury she is attempting to reverse, for example; and also in recognizing the limitations of her ability to restore the injured ecosystem.

If this is so, then it suggests among other things the importance of not separating too sharply the act of restoration or healing from the act of destruction or injury. Rather than denying the shame of injuring nature, or referring it to others, the restorationist should take advantage of the opportunity restoration offers to become aware of and to acknowledge her complicity in it. In other words, harm and restoration should not be seen or experienced separately, but should be tightly linked in a ritual cycle that leads through shame to community.

What this suggests, of course, is rather different from what most of us take for granted. But if this is so, it may be because our thinking rests on foundations laid by the Emersonians-a tradition of thought, we should remind ourselves, that Lewis identifies as lying at the root of modern alienation.

So far as I know, environmentalism has never built anything on the foundations laid by Hawthorne or Melville. Perhaps it should. And perhaps this is a task for restorationists.

William R. Jordan III 